\title{
Temalı Park Şirketlerinin Web Sitelerinin İçerik Analizi ile Değerlendirilmesi: Dünyadaki ve Türkiye'deki Örneklerin Kıyaslanması
}

DOI: $10.26466 /$ opus.735280

\author{
Muhammet Emin Soydaș - Emrah Göz ** \\ * Dr. Öğr. Üyesi, İskenderun Teknik Üyesi, Turizm Fakültesi, İskenderun/HATAY \\ E-Posta: mesoydas@gmail.com \\ ORCID: $0000-0002-3584-7303$ \\ ** İskenderun Teknik Üniversitesi, Sosyal Bilimler Enstitüsü, İskenderun/HATAY \\ E-Posta: emrahgoz@gmail.com \\ ORCID: 0000-0002-8912-4274
}

\begin{abstract}
Öz
Temalı parkların turizm talebi artışında önemli rol oynamaya başladı̆̆ı görülmektedir. Son yıllarda temalı parkların sayılarında artış gözlenirken, bu pazardaki rekabetin de arttığı görülmektedir. Temalı parklar, insanların bos zamanlarım değgerlendirmek amacıyla yaşadığg ortamdan uzaklaşarak farklı deneyimler kazanmak ve güzel vakit geçirmek için ziyaret ettikleri alanlar olarak ifade edilebilir. Temalı parklar aynı zamanda teknolojiyi de kulanan alanlar olarak görülmektedir. Bilgi teknolojilerindeki gelişme ile beraber işletme web sayfaları önem kazanmıştır. Satın alma karar sürecinde web sayfalarının sahip olduğu özellikler etkili olmaktadır. Yapılan bilimsel yayınlara bakıldı̆̆ında turizm amaçl satın almalarda çeorim içi satın almanın payının da gittikçe arttığı görülmektedir. Son yıllarda gittikçe artan bir ilgi ile karşı karşıya olan tematik parkların web sitelerinin durumunu ortaya koymaya çalışan bu çalışmada dünyada en çok ziyaretçi çeken ilk on temalı park web siteleri ile Türkiye'deki ilk on temalı parkların web siteleri içerik analizi ile ortaya konularak karşılaştırılmıştır. Yapılan analiz sonucunda, Türkiye'deki işletmelerin Web sayfalarının dünyada en fazla ziyaretçi kabul eden işletmeler kadar başarılı olmadıkları görülmüştür.
\end{abstract}

Anahtar Kelimeler: Temalı park, web sitesi, ziyaretçi, turizm, içerik analizi 


\title{
Evaluation of Themed Park Companies Web Sites Using Content Analysis: Comparison of the Samples in the World and in Turkey
}

\begin{abstract}
It is observed that the theme parks have started to play an important role in the increase in tourism demand. While there has been an increase in the number of themed parks in recent years, competition in this market has also increased. Themed parks can be expressed as areas that people visit to gain different experiences and have a good time by moving away from the environment in which they live. Theme parks also use technology. With the development of information technologies, business web pages have gained importance. The features of web pages are effective in the purchasing decision process. Considering the scientific publications, it is seen that the share of online purchases in tourism purchases is increasing. In this study, Web sites situation of themed parks, which has been increasingly attracted in recent years has been tried to reveal. Web sites of the top ten themed parks that most visited in the world and top ten themed parks in Turkey were evaluated by content analysis and compared. Results showed that web pages of companies in Turkey are not as successful as top ten themed parks that most visited in the world in terms of effective usage.
\end{abstract}

Keywords: Themed park, web site, visitor, tourism,content analysis 


\section{Giriş}

Dünya turizm hareketlerine katılanların sayısı her yıl artmaya devam etmektedir. Dünya Turizm Örgütü (UNWTO) verilerine göre; Uluslararası seyahat 2019 yılında \%4'lük artışla 1,5 milyar seviyesine ulaşmıştır. Bu oran 2017 (+\%7) ve 2018 (+6) yıllarından sonra 2019'da özellikle Avrupa'daki ekonomik durgunluk dikkate alınırsa yüksek bir ivme olduğu söylenebilir. Yine aynı rapora göre 2020 de ise \%3-\%4 arasında bir büyüme beklenmektedir (UNWTO, 2020). Ancak 2020 yılında Dünya genelinde görülen Covit-19’a bağlı olarak görülen salgın dolayısıyla bu öngörülen büyümenin gerçekleşemeyeceği söylenebilir. Bununla birlikte başlayan yeni normalleşme ile beraber tüm sektörlerde olduğu gibi turizm sektörü de bu duruma uyum sağlayarak devam edecektir.

Temalı parklar turizm talebinin üretilmesinde özel ve önemli bir rol oynamaktadır. Tema parkların sayıları son yıllarda gittikçe artarken, bu pazardaki rekabetin de büyüdüğ̈̈̈ gözlemlenmektedir. Sadece park sayısının artmasıyla değil, aynı zamanda multimedya gibi diğer kullanım alanlarına göre de yeni teknolojilerin tanıtımıyla yaratılan eğlence merkezleri daha cazip hale getirilmiştir. Temalı parklar, insanların bos zamanlarını değerlendirmek amacıyla yaşadığı ortamdan uzaklaşarak farklı deneyimler kazanmak ve güzel vakit geçirmek için ziyaret ettikleri alanlar olmaktadır (Swarbrooke, 1995; Middleton, 1988; Kemperman, 2000). Ziyaretçilerin bu deneyimlerinde eğlencenin yani sıra temalı parklar sayesinde kültürel anlamda zenginlikler de kazanırken, geçmiş ve gelecek zaman hakkında fikir edinebilecek, hayvanlarla da yakınlaşma fırsatı bularak onları daha yakından tanıyabilme fırsatına sahip olabilecekleri ifade edilebilir.

Turizm endüstrisi genellikle yenilik ve üretim sistemi olarak tanımlanmaktadır (Yıldız, 2011). Teknoloji, tüketicilerin seyahat edebilmesi için ekonomik yöntemler geliştirerek ekonomik büyümeyi gerçekleştirmede önemli bir rol oynamıştır. Bilgi teknolojisinin gelişimi ve ilerlemesi turizmde büyük bir etkiye sahiptir. İnternet teknolojileri sayesinde çevrim içi alışveriş oldukça yaygın hale gelmiştir (Aymankuy, Soydaş ve Saçlı, 2013). ABD'deki dört internet kullanıcısından üçü perakende ürün ve hizmetler için çevrimiçi satın alma gerçekleştirirken (Éthier, Hadaya, Talbot ve Cadieux 2006; Sun, Cardenas ve Harrill 2016), turizm amaçlı satın almada otel rezervasyonları, çevrim içi alışverişte hava yollarından sonra ikinci sırada gelmektedir (Conyette, 
2012). Wearesocial (2019) global İnternet ve ticaret kullanım raporuna göre İnternet üzerinden yapılan çevrim içi seyahat ve konaklama rezervasyonları 2018'de tüketici e-ticaret harcamaları içerisinde en büyük payı oluşturmaktadır (750 milyar ABD Doları). Çevrim içi satın alma eylemlerindeki artış web sitelerinin kullanım kolaylığı, kalitesi, ödeme güvenliği gibi çeşitli kriterleri gündeme getirmiştir.

Çevrim içi alışverişte web sitesi oluşturmaktaki temel amaç tüketicilere bilgi sağlamak ve müşteri memnuniyetini oluşturmak için bilgi sitemi ve hizmet kalitesini üst düzeyde tutmaktır (Ziaullah, Feng ve Akhter, 2014). Çevrim içi müşteri memnuniyeti yaratmak ve geliştirmek için rekabetçi bir tasarım, kolay kullanım, fiyat ve farklı ürün bilgileri sahip olunması gereken bazı özelliklerdendir (Park ve Kim, 2003). Çevrim içi satın alma deneyiminden memnun kalan tüketicilerin tekrar satın alma davranışı gösterdikleri, başkalarına tavsiye ettikleri ve fiyata daha az duyarlı davrandıkları belirtilmektedir (Homburg, Koschate ve Hoyer, 2005).

Bu çalışmanın amacı son yıllarda gittikçe artan bir ilgiyle karşı karşıya olan tematik parkların çevrim içi pazardaki durumlarını belirleyen unsurlardan biri olan web sitelerinin durumlarının ortaya konulmasıdır. Zira alan yazın taraması yapıldığında tematik parkların web sitelerine ilişkin herhangi bir çalışmaya rastlanılamamıştır. Bu amaçla belirlenen kriterler doğrultusunda Dünya'da en çok ziyaretçi çeken ilk on tematik parkın ve Türkiye'deki en çok ziyaretçi çeken ilk on tematik parkın web sitelerinin içerikleri analiz edilerek karşılaştırılmıştır. Karşılaştırma neticesinde Dünya' da en çok ziyaretçi alan ilk on temalı parka ait web sitelerinin sahip olduğu özellikler ile Türkiye'de yer alan temalı park web sitelerinin farklılık ya da benzerlikleri ortaya konulmuştur.

\section{Temalı Park Kavramı}

Tema parkları ile ilgili çalışmaların kısıtlı olduğu (Kemperman, 2000) dolayısıyla tanımlamalarında kısıtlı olduğu ifade edilebilir. Tema parkları ziyaretçi çekim merkezlerinin bir alt kümesi olarak tanımlamıştır. Ziyaretçi çekim merkezleri ise ziyaretçilerin zevk, eğlence, eğitim, hoş vakit geçirme amaciyla kalıcı olarak tasarlanan küçük ölçekli coğrafi alanlar olarak tanımlanmaktadır (Swarbrooke, 1995; Middleton, 1988). Bu alanlar doğal çekiciliklere sahip 
alanlar olabileceği gibi insan yapımı ziyaretçi çekim amacı güden ya da gütmeyen binalar, alanlar ya da özel etkinlikler olabilir. Tema parkı, ziyaretçi çekim merkezlerinin alt kümesi olmasına rağmen, özellikle eğlence çekiciliklerinde ziyaretçi yerlerini diğer türlerinden ayırt eden bazı özellikleri vardır. Bu özellikler (Kemperman, 2000):

- Bir defaya mahsus giriş ücreti veya birebir ücrete tabi cazibeler,

- Cazibeler çoğunlukla insan yapımı olması,

- Yüksek sermaye yatırımları gerektirmesi, olarak belirtilmektedir.

Tema parkları yüksek yatırım gerektiren insan yapımı, kullanıcı odaklı, oldukça gelişmiş eğlence alanlarıdır (Pearce, 1988). Forrec (2019) ise tema parklarını bir kaçış alanı olarak tanımlamaktadır. İnsanların sahip oldukları günlük sorumluluklarından biraz olsun kaçma şansı olarak ifade etmektedir. Eğlence, yiyecek içecek olanakları ve parka ilişkin yapılar belirli bir tema doğrultusunda tasarlanmaktadır. Uluslararası Eğlence Parkları ve Cazibe Merkezleri Birliği'ne (IAAPA) göre, "Bir tema parkı; yiyecek, kostüm, eğlence, perakende mağazaları ve gezilebilecek yerler gibi temalı cazibe merkezlerine sahip bir eğlence parkıdır." (IAAPA, 2019). Bu tanımlara göre tema park veya eğlence parkı belli bir temaya dayanan, birçok eğlence tesisinin bir araya gelmesiyle oluşan eğlence merkezi olmaktadır. Başka bir anlatımla tema parkları, acık ve kapalı alan seçenekleriyle genelde kalabalık insan gruplarına hitap eden farklı sayıda ve amaçta eğlence türlerine sahip olan (roller coaster, su parkları, hayvan krallığı vb.) ve belli bir temaya dayanan tesisleri seklinde ifade edilebilmektedir.

Tema parkları genel olarak ziyaretçilere başka bir yer ve zamanın atmosferini yaratmaya çalışırlar (Kemperman, 2000). Tema parkları bir tek tema sunmak yerine çoklu temalar içeren alanlar yaratmaktadırlar. Tema parklar yedi ana tema grubuna göre sınıflandırılmıştır (Wong ve Cheung, 1999). Bu sinıflandırma tablo 1'de verilmiştir. 
Tablo 1. Temalı Parklarn Sinıflandinlması

\begin{tabular}{|c|c|c|c|}
\hline Türler & Özellikler & Türler & Özellikler \\
\hline Macera & $\begin{array}{l}\text { Heyecanlı ve hareketli, } \\
\text { Ürkütücü, Gizemli, } \\
\text { Korku Trenleri. }\end{array}$ & Fantezi & $\begin{array}{l}\text { Animasyon, Çizgi film karakterleri, } \\
\text { Çocuksu çekicilik, Çocuk oyun park- } \\
\text { ları, Masallar, Büyü, İnanç yaratma, } \\
\text { Mitoloji ve efsane. }\end{array}$ \\
\hline Futurizm & $\begin{array}{l}\text { Geleceğin toplumu ve teknoloji, Bu- } \\
\text { luşlar, Bilimsel ve teknolojik keşifler, } \\
\text { Lazer, Robot, Bilim kurgu. }\end{array}$ & Tarih & $\begin{array}{l}\text { Yerliler, Otantik, Kültürel miras, Et- } \\
\text { nik farklılıklar, Altına hücum, } \\
\text { Tarihi ambiyans. }\end{array}$ \\
\hline Uluslararası & $\begin{array}{l}\text { Dünyanın tatları, Uluslararası köy, } \\
\text { Minyatür kopyalar, Manzara nokta- } \\
\text { ları, Dünya sergileri. }\end{array}$ & Film & $\begin{array}{l}\text { Amerikan Vahşi Batı gösterileri, } \\
\text { Komedi, Sinema filmciliği, Gösteriler, } \\
\text { Dublör gösterileri. }\end{array}$ \\
\hline Doğal & $\begin{array}{l}\text { Hayvanlar, Bitkisel sunum, } \\
\text { Doğal bahçeler, Çevre düzenlemesi, } \\
\text { Deniz ve denizcilik yaşamı, Doğal } \\
\text { harikalar, Okyanus Vahşi yaşam. }\end{array}$ & & \\
\hline
\end{tabular}

Kaynak: Wong, K. K. F. ve Cheung, P. W. Y. (1999). Strategic Theming In Theme Park Marketing. Journal Of Vacation Marketing, 5(4), 319-332.

\section{Turizm Endüstrisinde Web Siteleri}

1980'lerden itibaren teknolojinin gelişmesiyle birlikte meydana gelen değişim ve gelişimlerin sonucunda turizm endüstrisinin yapısı kadar işletmecilik uygulamaları ve stratejilerinde de çeşitli değişimler ortaya çıkmıştır (Buhalis ve Law, 2008; Ho ve Lee, 2007). İnternet üzerinden bilgiye erişimin daha kolay ve daha az maliyetli olması 90 'ların başında dünya çapında \%1 olan internet kullanıcısı oranını bir hayli arttırarak 2016 yılında 3 milyar, 2019 yılında ise 4 milyar kişinin üzerine çıarmıştır (statista.com; wearesocial.com; Kim, Lehto ve Morrison, 2007). Ayrıca; tripadvisor.com'a göre; dünya çapında turistlerin $\% 89$ 'u konaklama seçimi yaparken çevrim içi seyahat yorumlarından etkilenmektedir. İnternet'in hızl gelişimi sosyal medyanın da etkisini artırmış ve tatil kararlarında etkin hale gelmiştir (Aymankuy, vd., 2013). Bu bağlamda turistlerin internet üzerinden edindikleri bilgiler, seyahat deneyimlerini geliştirirken aynı zamanda belirsizlikleri de ortadan kaldırmaktadır.

Bağlantı, iletişim ve ilgili faaliyetlere dayanan turizm endüstrisinde dijital pazarlama tüm bu nedenlerden dolayı oldukça önemlidir (Braun, 2002). Turizm endüstrisinde dijitalleşme ile birlikte Hojeghan ve Esfangareh (2011), rekabet çevresinin turizm endüstrisi için yeni ve büyük fırsatlar yarattığını ifade ederken aynı zamanda değişmeyenler ya da değişime uyum sağlamayanlar için de büyük risk olduğunu dile getirmiştir. 
Bilgi teknolojileri ve İnternet' in gelişimi, elektronik dağıtım araçları kullanımı turizm işletmelerini pazarda var olmasını sağlamakla beraber etkin kullanımı rakiplere göre üstünlük kurmalarını sağlamaktadır. Bilgi iletişim teknolojilerinin evriminin sonucu olarak tüketiciler için dünya çapında destinasyonları araştırmak daha kolay hale gelmiştir. Bohur ve Kirali (2015) teknolojik değişimlerin çok hızlı olmasından kaynaklı olarak seyahat acenteleri ve tur operatörlerinin gücünün sarsılmakta olduğunu, gelişen dijital ekonomiye uyum sağlamaları gerektiğini ifade etmişlerdir.

Dijital ekonominin en önemli araçlarından bir tanesi de web siteleridir. Web siteleri işletmelerin sanal ortamda var olmalarının bir aracıdır. Dolay1sıyla tasarımı, kullanışlılığı, güvenilirliği, erişilebilirliği vb. önem arz etmektedir. Web sitesi tasarımında işletmelerin istek, beklenti ve stratejilerinin yanında tüketici istek ve beklentileri de dikkate alınmalıdır. Alan yazın taraması yapıldığında tematik parkların web sitelerine ilişkin herhangi bir çalışmaya rastlanılamamıştır. Bunun yanında konaklama (Karamustafa vd., 2002; Ranganathan ve Ganapathy, 2002; Jeong ve Oh, 2005; Law ve Cheung, 2005; Law ve Hsu, 2006; Kim, Ma ve Kim, 2006; Purnawan, 2011; Salem ve Cavlek, 2016; Ateş ve Boz, 2015; Islam ve Nevenka, 2016; Asmadili ve Yüksek, 2018), yiyecek içecek (Moreo, Çobanoğlu ve DeMicco, 2007; Dalgin ve Karadağ, 2013; Özdipçiner ve Ceylan, 2017; Güdük ve Uca, 2017) ve seyahat işletmeleri (Park, 2002; Hançer ve Ataman, 2006) web sayfalarına yönelik çalışmalar mevcuttur.

Konaklama işletmelerine yönelik Law ve Hsu (2006) tarafından yapılan çalışmada katılımcılar tarafından önemli olarak algılanan 5 boyut ortaya konmuştur. Bu boyutlar: 1) Rezervasyon bilgileri, 2) tesis bilgileri, 3) iletişim bilgileri, 4) çevre bilgileri, 5) web sitesi yönetimi. Boyutlara genel olarak bakıld1ğında; rezervasyon bilgilerinde, oda fiyatları, gerçek zamanlı rezervasyonlar ve güvenli ödeme sistemleri ön plana çıarken; Tesis bilgilerinde otelin konumu belirginleşmiştir. İletişim bilgilerinde, telefon, adres ve e-posta adresi önemli bulunurken; çevreleyen alan bilgisinde ulaşım; web sitesi yönetiminde de sitenin güncellenmesi ön plana çımıştır. Bu boyutlar içerisinde rezervasyon bilgileri katılımcılar tarafindan en önemli unsur olarak ortaya konmuştur. Shoemaker, Lewis ve Yesawich (2007) de rezervasyon bilgilerinin yanında web sayfası üzerinden rezervasyon yapabilmenin önemini vurgulamıştır. Bu durum potansiyel tüketicileri aktif tüketiciye dönüştürme imkanı 
yaratmaktadır. Rezervasyon uygulaması olmayan bir web sayfası bir bilgi broşüründen başka bir şey olamayacaktır (Hsu, Zhu ve Agrusa, 2004).

Jeong ve Oh (2005) konaklama işletmeleri web sitesi kalitesi ve satın alma davranışı ile ilgili yaptıkları çalışmada web sitesi bilgi memnuniyetine tüketiciler tarafından önem verildiği ve satın alma davranışını etkilediğini belirtmişlerdir.

Islam ve Nevenka (2016) çalışmalarında otel web sitelerinin içeriğinin önemini müssteri bakış açısıyla değerlendirmişlerdir. Bu amaçla öncelikle beş yıldızlı otel işletmelerinin web sayfalarının mevcut durumlarını ortaya koymuş ve otel müşterilerine anket uygulayarak ta web siteleri ile ilgili müşteri görüşlerini belirlemişlerdir.

Purnawan (2011) Singapur'daki otel işletmeleri web siteleri üzerine müşteri odaklı, teknik yeterliliğe sahip, güncel bilgi içeren ve pazarlama açısından etkin, çevrim içi satış özelliklerini dikkate alan bir çalışma gerçekleştirmiştir. Çalışma sonucunda örneklem içerisinde yer alan her dört otelden üçünün web sitesini etkin kullandığı ve dinamik bir yapıya sahip olduğu ortaya konmuştur. Bunun yanında bazı web sitelerinin ise etkileşimli olmadığı, çevrim içi satışa olanak vermediği dolayısıyla sadece bir bilgi broşürü gibi hizmet verdiklerini ifade etmiştir.

Law ve Cheung (2005) Hong Kong otelleri web sitelerini kapsayan çalışmasında tüketici bazlı değerlendirme sonucunda rezervasyon bilgileri, web sitesi yönetimi boyutlarının en önemli unsurlar olduğunu ortaya koymuşlardir.

Ateş ve Boz (2015) Çanakkale'de 3, 4 ve 5 yıldızlı otellerin web sitelerini içerik analizi yöntemiyle değerlendirmiş ve sonuç olarak web sitelerinin etkin kullanılmadığı, durağan bir yapıya sahip oldukları ve güncelleme yapmadıkları belirlenmiştir.

Asmadili ve Yüksek (2018) Eskişehir'deki turizm işletme belgeli otellerin web sitelerini içerik analizi yöntemiyle incelemiştir. Analiz sonucunda web sayfalarının önemli bir kısmında çevrim içi yardım formu, döviz kuru bilgisi, çevrim içi anket, öneri formu ve ziyaretçi defteri gibi özelliklerin bulunmadığı belirlenmiştir. Web sitelerinin durağan olmaması, etkileşimli olması ve pazarlama açısından daha etkin kullanılması gerektiği vurgulanmıştır.

Ranganathan ve Ganapathy (2002), çevrimiçi tüketiciler tarafından algılanan işletmeler arası web sitelerinin temel boyutlarını türetmek için bir çalışma yapmıştır. Tüketicilerin web sitesinin etkinliği konusundaki görüşleri, 
içerik ve tasarım altında sınıflandırılabilecek temel özelliklerden etkilenmektedir. Çalışma sonucunda bilgi içeriği, tasarım, güvenlik ve mahremiyet olmak üzere dört boyut ortaya koyarken, bunlardan güvenlik boyutunun çevrimiçi satın alma niyeti açısından en önemli unsur olarak ortaya çıktı̆̆ını vurgulamışlardır.

Moreo, Cobanoğlu ve de Micco (2007), ticari restoran web siteleri ile üniversitelerin turizm ve otelcilik programı restoranlarının web sitelerini karşılaştırmış ve sitenin çekiciliği, kullanım kolaylığı, iletişim kolaylığı, pazarlama etkinliği ve yasal uygunluk kriterleri doğrultusunda değerlendirmişlerdir. Sonuç olarak üniversite restoranlarının web sayfalarının ticari restoran web sayfalarından geri kaldığı ve kendilerini geliştirmeleri gerektiği ortaya konmuştur.

Dalgın ve Karadağ (2013), Bodrum ve Marmaris restoranları web sitelerini analiz etmişler ve internet teknolojilerini etkin olarak kullanan restoran sayısının kısıtlı olduğu ancak sosyal medyayı önemli bir kısmının kullandığını belirtmişlerdir. Web sayfalarının görsel öğe ve iletişim bilgileri açısından yeterli olduğu fakat kullanım kolaylığı ve içerik bakımından yetersiz olduklarını belirtmişlerdir.

Güdük ve Uca (2017), Birinci sınıf restoran web sitelerini içerik analizi yöntemiyle incelemiş ve bazı temel özelliklerin web sitelerinde bulunmasına rağmen, müşteri deneyimlerini ve tercihlerini olumlu yönde etkileyebilecek tasarım ve pazarlama özellikleri açısından yetersiz kaldığını tespit etmişlerdir.

Konu ile ilgili çalışmalara bakıldığında web sitelerinin günümüzde pazarlama açısından zorunlu araçlardan bir tanesi haline geldiği ve işletmeler açısından etkin kullanımının kaçınılmaz olduğu ortaya çıkmaktadır. Çevrim içi satın alma işlemleri değişen tüketici davranışları ile beraber hızla artmaktadır. Bununla beraber tüketicilerin çevrim içi satın alma işleminde web sitesinden farklı beklentileri olduğu ve önem düzeylerinin de değiştiği görülmektedir. Web siteleri herhangi bir mal ya da hizmeti satın alma niyetinde olan tüketicilerin başvurduğu birincil kaynaklar haline geldiği dolayısıyla çevrim içi pazarda yer almak isteyen işletmelerin bu faktörler ve önem düzeylerini dikkate almaları gerektiği söylenebilir. 


\section{Metodoloji}

Bu çalışmanın ilgi alanı temalı parkların web siteleridir. Son yıllarda gittikçe artan bir ilgiyle karşı karşıya olan tematik parkların çevrim içi pazardaki durumların belirleyen unsurlardan biri olan web sitelerinin durumlarının ortaya konulması amaçlanmıştır. Zira alan yazın taraması yapıldığında tematik parkların web sitelerine ilişkin çalışmaya rastlanılamamıştır. Bu amaçla Dünya'nın ve Türkiye'nin en çok ziyaretçi çeken ilk on tematik parkının web siteleri içerik analizi yapılarak değerlendirilmiş ve karşılaştırılmıştır.

Dünya'da en çok ziyaretçi alan temalı park grupları Themed Entertainment Association tarafından hazırlanan "Global Attractions Attendance Report 2018" (TEA, aecom.com) raporundan elde edilmiş ve aşağıda sunulmuştur:

1.Walt Disney

2.Merlin Entertainment

3.Universal

4.Oct Parks China

5.Fantawild

6.Chimelong Group

7.Six Flags Inc.

8.Cedar Fair Entertainment

9.Seaworld Parks \& Entertainments

10.Paraques Reunidos

Türkiye'deki tematik parkların ziyaretçi sayıları ile ilgili bir veriye ulaşılamadığından, Tripadvisor üzerinde en çok yorum alan ilk 10 temalı park dikkate alınmış ve aşağıda sunulmuştur:

1.Antalya Akvaryum

2.The Land of Legends Theme Park

3.Aqua Dream Su Parkı

4.İstanbul Akvaryum

5.Izmir Dogal Yasam Park1

6.Aqualand \& Dolphinland

7.Isfanbul

8.Water Planet Aqua Park

9.Dolphin Park Marmaris

10.Legoland Discovrey Centre 
Elde edilen liste doğrultusunda tematik park web sayfaları içerik analizi yöntemi ile değerlendirilmiştir. Kerlinger (1986), içerik analizini, değişkenleri ölçmek amaciyla iletişimi sistematik ve objektif bir şekilde incelemek ve analiz etmek için bir yöntem olarak tanımlamıştır. Bu analiz sürecinde amaç, mevcut durumu değiştirmeden, var olanı ortaya koymaktır. Bu amaçla, Islam ve Nevenka'nın (2016) otel web siteleri içeriklerini değerlendirdikleri çalı̧̧mada kullanılan kriterlerden yararlanılarak temalı parkların web siteleri için uyarlanmıştır. İçerik analizi yapmak için oluşturulan boyut ve kriterler tablo 2'de gösterilmiştir.

Tablo 2. Web sitesinin boyutlan ve içerikleri

\begin{tabular}{|c|c|}
\hline İşletme Bilgileri & $\begin{array}{l}\text { 1-Site için genel açıklama } \\
\text { 2-İsletmenin tanımı } \\
\text { 3-Temalı park özelliklerinin tanımı } \\
\text { 4-Farklı aktiviteler / eğlence tanımları } \\
\text { 5-Restoran için açıklama } \\
\text { 6-Barlar için açıklama } \\
\text { 7-Yardım merkezi için açıklama } \\
\text { 8-Mağazalar / hediye mağazaları için açıklama } \\
\text { 9-Mobil uygulamalar }\end{array}$ \\
\hline Çevreleyen Alan Bilgisi: & $\begin{array}{l}\text { 1-Alanın kısa tanımı } \\
\text { 2-Haritanın kullanılabilirliği } \\
\text { 3-Mesafeler için tanım } \\
\text { 4-İlgi alanları için açıklama } \\
\text { 5-Ulaşım yolları için açıklama } \\
\text { 6-Hava durumu bilgilerinin kullanılabilirliği }\end{array}$ \\
\hline Müşteri iletişim Bilgileri: & $\begin{array}{l}\text { 1-Adres } \\
\text { 2-Telefon bilgilerinin kullanılabilirliği } \\
\text { 3-E-posta adresinin kullanılabilirliği } \\
\text { 4-Şikayet formu } \\
\text { 5-Sık sorulan sorular } \\
\text { 6-Bülten } \\
\text { 7-Duyurular } \\
\text { 8-Oneriler } \\
\text { 9-24 saat çevrim içi yardım odası } \\
\text { 10-Sosyal medya }\end{array}$ \\
\hline Rezervasyon-Fiyat Bilgisi: & $\begin{array}{l}\text { 1-Ortalama fiyatlar } \\
\text { 2-Çevrimiçi kullanılabilirlik } \\
\text { 3-İnternet üzerinden rezervasyon imkanı } \\
\text { 4-Paketlerin / promosyonların kullanılabilirliği } \\
\text { 5-Özel tekliflerin uygunluğu } \\
\text { 6-Kabul edilen kart türleri hakkında bilgi } \\
\text { 7-Grup promosyonları / üyeleri }\end{array}$ \\
\hline Web Sitesinin Yönetimi: & $\begin{array}{l}\text { 1-Fotograf Albümü / Fotoğraflar } \\
\text { 2-Çoklu dil } \\
\text { 3-Fotoğraf videosu / sanal tur } \\
\text { 4-Oturum açlabilirliği } \\
\text { 5-Arama motorları / linkleri }\end{array}$ \\
\hline
\end{tabular}


Her boyut altında yer alan kriter sayısı o boyutun toplam puanını vermektedir: İşletme Bilgileri (9), Çevreleyen alan bilgisi (6), Müşteri iletişim bilgileri (10), Rezervasyon ve fiyat bilgisi (7), Web sitesinin yönetimi (5). Web sayfaları analizi yapılırken işletmelerin isimlerini kullanmak yerine kodlama yapmak ve sonuçları bu kodlamalar ile vermek tercih edilmiştir. Bu nedenle Dünyanın en fazla ziyaretçi alan temalı parklarını A1'den A10'a kadar, Türkiye'deki temalı parkları ise B1'den B10'a kadar kodlanmıştır. Web sayfaları incelenirken boyutlarda belirlenen kriterlerden eğer web sayfasında var ise 1, yok ise 0 vermek suretiyle web sayfalarını belirlenen kriterlere sahip olup olmama durumları ortaya konmuştur.

Karşılaştırma neticesinde Dünya'da en çok ziyaretçi alan ilk on temalı parka ait web sitelerinin sahip olduğu özellikler ile Türkiye'de yer alan temalı park web sitelerinin farklılık ya da benzerlikleri ortaya konulmuştur. Web sitelerinin değerlendirilmesi çalışması 06.06.2019 ile 20.06.2019 tarihleri arasında iki araştırmacı tarafından ayrı ayrı yapılıp daha sonra karşılaştırılarak hata payı minimuma indirilmeye çalışılmıştır.

\section{Bulgular ve Değerlendirme}

Bu çalışmada Dünya'da en çok ziyaretçi kabul eden (aecom.com) ve Türkiye'de en fazla yorum alan ilk on temalı park (tripadvisor.com) web sitelerinin içerik analizi ile değerlendirilmesi ve karşılaştırmasının yapılması amaçlanmıştır. Bu amaçla, öncelikle Dünya' da en çok ziyaretçi kabul eden işletme web sayfalarına ilişkin bulgulara yer verilecek, daha sonra ise Türkiye'deki işletmelerin web sayfalarının durumları ortaya konacaktır.

Dünya'nın en fazla ziyaretçi alan ilk on temalı park şirketlerinin web sayfaların içerik analizi ile değerlendirilmiş ve bu değerlendirmeye ilişkin sonuçlar tablo 3'te verilmiştir.

Tablo 3. Dünya'nın En Fazla Ziyaretçi Alan 10 Temalı Park Isşletmeleri ile ilgili Web Sitelerinin Incelenmesi.

\begin{tabular}{|c|c|c|c|c|c|c|c|c|c|c|c|c|}
\hline & \multicolumn{2}{|c|}{$\begin{array}{l}\text { İşletme } \\
\text { Bilgileri } \\
(9)\end{array}$} & \multicolumn{2}{|c|}{$\begin{array}{l}\text { Çevreleyen alan } \\
\text { bilgisi (6) }\end{array}$} & \multicolumn{2}{|c|}{$\begin{array}{l}\text { Müşteri iletişim } \\
\text { bilgileri (10) }\end{array}$} & \multicolumn{2}{|c|}{$\begin{array}{l}\text { Rezervasyon ve } \\
\text { fiyat bilgisi (7) }\end{array}$} & \multicolumn{2}{|c|}{$\begin{array}{l}\text { Web sitesinin } \\
\text { Yönetimi (5) }\end{array}$} & \multicolumn{2}{|c|}{ Toplam (37) } \\
\hline & $\mathrm{P}$ & $\%$ & $\mathrm{P}$ & $\%$ & $\mathrm{P}$ & $\%$ & $\mathrm{P}$ & $\%$ & $\mathrm{P}$ & $\%$ & $\mathrm{P}$ & $\%$ \\
\hline A1 & 9 & 100 & 5 & 83.3 & 9 & 90 & 7 & 100 & 4 & 80 & 34 & 91.8 \\
\hline $\mathrm{A} 2$ & 9 & 100 & 5 & 83.3 & 8 & 80 & 7 & 100 & 3 & 60 & 32 & 86.4 \\
\hline A3 & 9 & 100 & 6 & 100 & 9 & 90 & 7 & 100 & 4 & 80 & 35 & 94.5 \\
\hline A4 & 6 & 66.6 & 2 & 33.3 & 1 & 10 & 0 & 0 & 2 & 40 & 11 & 29.7 \\
\hline
\end{tabular}




\begin{tabular}{lllllllllllll}
\hline A5 & 8 & 88.8 & 5 & 83.3 & 8 & 80 & 7 & 100 & 3 & 60 & 31 & 83.7 \\
\hline A6 & 8 & 88.8 & 5 & 83.3 & 8 & 80 & 7 & 100 & 4 & 80 & 32 & 86,4 \\
\hline A7 & 7 & 77.7 & 5 & 83.3 & 8 & 80 & 7 & 100 & 4 & 80 & 31 & 83.7 \\
\hline A8 & 9 & 100 & 5 & 83.3 & 8 & 80 & 7 & 100 & 3 & 60 & 32 & 86.4 \\
\hline A9 & 9 & 100 & 5 & 83.3 & 8 & 80 & 7 & 100 & 4 & 80 & 33 & 89.1 \\
\hline A10 & 8 & 88.8 & 5 & 83.3 & 8 & 80 & 7 & 100 & 3 & 60 & 31 & 83.7 \\
\hline
\end{tabular}

Tablo 3 incelendiğinde A1, A2, A3, A8 ve A9 kodlu işletmelerin işletme bilgileri boyutundaki tüm bilgilere sahip oldukları görülmektedir. A5, A6 ve A10 kodlu işletmelerin ise toplam 9 özellikten 8'ine sahip olduğu, A4 kodlu işletmenin ise yardım merkezi ve mağazalarla ilgili açıklama ve mobil uygulama içeriklerine sahip olmadığı anlaşılmaktadır. Bu boyuta A4 kodlu işletmenin diğer işletmelere göre daha az önem verdiği görülmektedir. Genel olarak işletme bilgileri boyutuna önem verildiği ve web sayfalarında yer verildiği söylenebilir.

Çevreleyen alan bilgileri alanın kısa tanımı, haritanın kullanılabilirliği, mesafeler için tanım, ilgi alanları için açıklama, hava durumu bilgileri özelliklerini içermektedir. Bu boyuttaki özelliklerin tamamına sadece A3 kodlu işletmenin web sayfasının sahip olduğu görülmektedir. Diğer işletme web sayfaları ile kıyaslandığında hava durumu özelliğinin fark yarattı̆ı görülmektedir. Diğer işletme web sayfalarının ise bu boyutun hava durumu dışındaki diğer tüm özelliklere sahip olduğu tablodan anlaşılmaktadır.

Müşteri iletişim bilgileri boyutu, adres, telefon bilgileri, e-posta, şikayet formu, sık sorulan sorular, bülten, duyurular, öneriler, 24 saat çevrim içi yardım ve sosyal medya bağlantılarını içermektedir. Tablo incelendiğinde bu boyutta yer alan 10 özelliğe sahip olan bir web sayfası görülmemektedir. Bunun yanında A1 ve A3 kodlu işletme web sayfaları mevcut özelliklerin \%90'ına sahip iken A4 kodlu işletmenin web sayfasının ise sadece 1 özelliğe sahip olduğu görülmektedir.

Rezervasyon ve fiyat bilgileri boyutu, fiyat, çevrim içi kullanılabilirlik, çevrim içi rezervasyon imkanı, paket-promosyon ürün kullanımı, özel teklifler, kabul edilen kredi kartları bilgisi, grup promosyonları özelliklerini içermektedir. Tablo incelendiğinde bu boyutta A4 kodlu işletmenin web sayfasında bu 7 özellikten hiçbirinin kullanılabilir olmadığı anlaşılırken, diğer 9 işletme web sayfasının tüm özelliklere sahip olduğu görülmektedir. Law ve Hsu (2006), Law ve Cheung (2005), çalışmalarında en önemli boyut olarak ortaya koydukları rezervasyon ve fiyat bilgilerine çoğunlukla önem verildiği görülmektedir. 
Son boyut olan web sitesi yönetimi ise fotoğraf albümü-galerisi, çoklu dil seçeneği, sanal tur, oturum açlabilirliği ve arama motoru linklerinden oluşmaktadır. Tablo incelendiğinde A1, A3, A6, A7 ve A9 kodlu işletmelerin bu özelliklerin \%80'ine sahip olduğu görülmektedir. Bu boyutta da A4 kodlu işletme web sayfasının \%40 ile en az özelliğe sahip olduğu söylenebilir.

Tüm işletme web sayfaları genel olarak değerlendirildiğine A3 kodlu işletmenin 35 puan ve \%94.5 ile en fazla özelliğe sahip web sayfası olduğu bunu \%91.8 ile A1 ve 89.1 ile A9 kodlu işletme web sayfaları takip etmektedir. A4 kodlu işletme ise \%29,7 ile ilk 10 içerisinde yer alan web siteleri içerisinde en az özelliğe sahip olan olarak görülmektedir. A4 kodlu işletme dışında ilk 10 'da yer alan işletmelerin web sitelerine önem verdikleri söylenebilir. Web sayfalarını aktif olarak kullandıkları, web sayfalarını pazarlama iletişiminin önemi doğrultusunda kullandıkları ifade edilebilir.

Tablo 4, Türkiye'deki temalı parklardan Tripadvisor sitesinde en fazla yorum alan ilk 10 tema park işletmesinin web sayfaları analizini göstermektedir.

Tablo 4. Türkiye'deki ilk 10 temalı park web sitesi analizi

\begin{tabular}{|c|c|c|c|c|c|c|c|c|c|c|c|c|}
\hline & \multicolumn{2}{|c|}{$\begin{array}{l}\text { İşletme } \\
\text { bilgileri (9) }\end{array}$} & \multicolumn{2}{|c|}{$\begin{array}{l}\text { Çevreleyen alan } \\
\text { bilgisi (6) }\end{array}$} & \multicolumn{2}{|c|}{$\begin{array}{l}\text { Müşteri iletişim } \\
\text { bilgileri (10) }\end{array}$} & \multicolumn{2}{|c|}{$\begin{array}{l}\text { Rezervasyon } \\
\text { ve fiyat } \\
\text { bilgisi (7) }\end{array}$} & \multicolumn{2}{|c|}{$\begin{array}{l}\text { Web sitesinin } \\
\text { Yönetimi (5) }\end{array}$} & \multicolumn{2}{|c|}{ Toplam (37) } \\
\hline & $\mathrm{P}$ & $\%$ & $\mathrm{P}$ & $\%$ & $\mathrm{P}$ & $\%$ & $\mathrm{P}$ & $\%$ & $\mathrm{P}$ & $\%$ & $\mathrm{P}$ & $\%$ \\
\hline B1 & 6 & 66.6 & 5 & 83.3 & 10 & 100 & 6 & 85.7 & 3 & 60 & 30 & 81 \\
\hline B2 & 6 & 66.6 & 5 & 83.3 & 7 & 70 & 6 & 85.7 & 3 & 60 & 27 & 72.9 \\
\hline B3 & 7 & 77.7 & 5 & 83.3 & 7 & 70 & 6 & 85.7 & 3 & 60 & 28 & 75.6 \\
\hline B4 & 7 & 77.7 & 5 & 83.3 & 10 & 100 & 6 & 85.7 & 4 & 80 & 32 & 86.4 \\
\hline B5 & 5 & 55.5 & 5 & 83.3 & 10 & 100 & 0 & 0 & 3 & 60 & 23 & 62.1 \\
\hline B6 & 7 & 77.7 & 6 & 100 & 6 & 60 & 7 & 100 & 3 & 60 & 29 & 78.3 \\
\hline B7 & 7 & 77.7 & 5 & 83.3 & 10 & 100 & 6 & 85.7 & 3 & 60 & 31 & 83.7 \\
\hline B8 & 7 & 77.7 & 5 & 83.3 & 7 & 70 & 0 & 0 & 3 & 60 & 22 & 59.4 \\
\hline B9 & 7 & 77.7 & 5 & 83.3 & 6 & 60 & 7 & 100 & 3 & 60 & 28 & 75.6 \\
\hline B10 & 9 & 100 & 5 & 83.3 & 10 & 100 & 7 & 100 & 3 & 60 & 34 & 91.8 \\
\hline
\end{tabular}

Tablo 4 incelendiğinde işletme bilgileri boyutundaki tüm özelliklere sahip tek bir işletme olduğu görülmektedir. B10 kodlu işletmenin web sayfası işletme bilgileri boyutunda \%100 ile tüm özelliklerin yer aldığı bir web sayfasına sahip olduğu görülmektedir. B3, B4, B6, B7, B8 ve B9 işletmeleri ise \%77.7 sahip olma oranına sahiptir. B1 kodlu işletme 6 puana sahip iken B5 kodlu 
işletme web sayfası 5 puan ile son sırada gelmektedir. Bu boyutta mobil uygulamaya ilişkin bilgiler sadece 1 işletme web sayfasında yer alırken diğer bir eksiklik ise barlara ilişkin bilgilerin olmayışı olarak ortaya çıkmaktadır.

Çevreleyen alan bilgisi boyutunda da sadece 1 işletme web sayfası tüm özelliklere sahip iken diğer işletme web sitelerinin de 6 özellikten 5'ine sahip olduğu görülmektedir. Bu boyuttaki bilgilerin web sayfasında yer alma oranının diğer boyutlara göre daha fazla olduğu görülmektedir.

Müşteri iletişim bilgileri boyutuna bakıldığında B1, B4, B5, B7, B10 kodlu işletmelerin web sayfalarının \%100 ile tüm özelliklere sahip olduğu, B2, B3 ve B8 kodlu işletmelerin web sayfalarının \%70 ve B6 ve B9 kodlu işletmelerin web sayfalarının ise \%60 oranında özelliklere sahip olduğu görülmektedir. Bu boyut genel olarak değerlendirildiğinde sadece B2 kodlu işletmenin telefon bilgileri ve e-posta bilgisinin olmadığı, B1, B2, B7 ve B10 kodlu işletmelerin web sayfalarında 24 saat çevrim içi yardım özelliğinin bulunduğu görülmektedir.

Rezervasyon ve fiyat bilgileri boyutuna bakıldığında B5 ve B8 kodlu işletme web sitelerinin 0 puan aldığ 1 ve rezervasyon ve fiyata ilişkin herhangi bir bilgiye sahip olmadığı görülmektedir. Bunun yanında B6, B9 ve B10 kodlu işletme web sayfalarının ise bu boyutta yer alan tüm özelliklere sahip olduğu görülmektedir.

Web sitesi yönetimi boyutunda ise sadece B4 kodlu işletmenin 5 özellikten 4'üne sahip olduğu, diğer işletmelerin ise \%60 oranında bu boyut özelliklerine sahip olduğu görülmektedir.

Tüm işletme web sayfaları genel olarak değerlendirildiğinde B10 kodlu işletmenin 37 özellikten 35'ine sahip olarak en fazla özelliğe sahip web sayfası olduğu ortaya çıkmaktadır. Bunu 32 puan ile B4, 31 puan ile B7, 30 puan ile B1 kodlu işletme takip etmektedir. B8 kodlu işletme web sayfası ise 22 puan ile son sırada gelmektedir. Çevreleyen alan bilgisi ile rezervasyon ve fiyat boyutunun en fazla önem verilen boyutlar olduğu da ifade edilebilir.

\section{Sonuç}

Bu çalışmada son yıllarda gittikçe artan bir ilgiyle karşı karşıya olan tematik parkların çevrim içi pazardaki durumlarını belirleyen unsurlardan biri olan web sitelerinin durumları ortaya konulmaya çalışılmıştır. Bu amaçla Dünyada en çok ziyaretçi çeken ilk on tematik park ve Türkiye'de ilk on tematik 
park web siteleri içerik analizi yapılarak değerlendirilmiş ve karşılaştırılmıştir.

Tablo 5 dünyada en fazla ziyaretçi alan tematik parkların web siteleri ile Türkiye'deki tematik parkların web sitelerinin analiz sonuçlarını işletme bazında göstermektedir.

Tablo 5. Dünyada en fazla ziyaretçi alan tematik park işletmeleri ve Türkiye'de en fazla yorum alan tematik parklarn web site analiz sonuçları

\begin{tabular}{lllllll}
\multicolumn{2}{l}{ Dünyada en fazla ziyaretçi alan tematik park işletmeleri } & \multicolumn{3}{c}{ Türkiye'deki tematik park işletmeleri } \\
\hline \multicolumn{2}{c}{ Puan } & $\mathbf{\%}$ & & Puan & \% \\
\hline A1 & 34 & 91.8 & B1 & 30 & 81 \\
\hline A2 & 32 & 86.4 & B2 & 27 & 72.9 \\
\hline A3 & 35 & 94.5 & B3 & 28 & 75.6 \\
\hline A4 & 11 & 29.7 & B4 & 32 & 86.4 \\
\hline A5 & 31 & 83.7 & B5 & 23 & 62.1 \\
\hline A6 & 32 & 86.4 & B6 & 29 & 78.3 \\
\hline A7 & 31 & 83.7 & B7 & 31 & 83.7 \\
\hline A8 & 32 & 86.4 & B8 & 22 & 59.4 \\
\hline A9 & 33 & 89.1 & B9 & 28 & 75.6 \\
\hline A10 & 31 & 83.7 & B10 & 35 & 94.5 \\
\hline
\end{tabular}

Bu tabloya göre tematik park web sitelerinin sahip olması gereken 5 boyut ve 37 özellik dikkate alındığında, \%94.5 ile A3 ve B10 kodlu işletmeler ilk sırayı almaktadır. Dolayısıyla Türkiye' de yer alan bir tematik park işletme web sayfası Dünya'da en çok ziyaretçi alan bir tematik park işletmesi web sayfası ile aynı özelliklere sahip olduğu söylenebilir. Web sayfalarının pazarlama iletişimi açısından önemine binaen Dünya genelindeki rakipleri kadar önem verdikleri söylenebilir. Ancak bu durum Türkiye'deki diğer tematik park işletmesi web siteleri için söylenemeyebilir. Zira A3 kodlu işletmenin ardından\%91.8 ile A1, \%89.1 ile A9, \%86.4 ile A2, A6 ve A8 işletmeleri gelmektedir. Türkiye'deki işletme web sayfalarına baktığımızda B10 işletmesinin ardından \%86,4 ile B4, \%83.7 ile B7, \%81 ile B1 \%78.3 ile B6 işletmesi gelmektedir. Genel olarak bakıldığında Türkiye'deki işletmelerin web sayfalarının Dünya'da en çok ziyaretçi kabul eden işletme web sayfaları kadar başarılı oldukları söylenemeyebilir.

Tablo 6 dünyada en fazla ziyaretçi alan tematik parklar ile Türkiye'deki tematik park işletme web sitelerinin durumlarının boyutlar düzeyinde karşılaştırmasını göstermektedir. 
Tablo 6. Boyutlar düzeyinde tematik park işletme web sayfalarnın durumlan

\begin{tabular}{lllll}
\hline & Dünya'da & \multicolumn{3}{c}{ Türkiye'de } \\
\hline Puan ve yüzde & Puan & $\%$ & Puan & $\%$ \\
\hline İşletme bilgileri (90) & 82 & 91.1 & 68 & 75.5 \\
\hline Çevreleyen alan bilgisi (54) & 48 & 88.8 & 51 & 94.4 \\
\hline Müşteri iletişim bilgileri (100) & 75 & 75 & 83 & 83 \\
\hline Rezervasyon ve fiyat bilgisi (70) & 63 & 90 & 51 & 72.8 \\
\hline Web sitesinin yönetimi (50) & 34 & 68 & 31 & 62 \\
\hline Toplam (364) & 302 & 82.9 & 284 & 78.1 \\
\hline
\end{tabular}

Bu tablo incelendiğinde işletme bilgileri boyutunda dünyada en çok ziyaret edilen işletmelerin web sitelerinin Türkiye'de en çok yorum alan işletmelerin web sitelerinden toplamda daha fazla puan aldıkları ve bu konuda daha başarılı oldukları gözlemlenmiştir. Bu boyuttaki mobil uygulama ve mağazalar için açıklama içeriklerine dikkat edildiğinde, Dünya'daki en çok ziyaretçi alan işletmelerin bu konuya gereken önemi verdikleri bulgular sonucunda söylenebilir. İşletme bilgileri boyutunda yer alan mobil uygulaması dikkat edilmesi gereken bir içeriktir. Dünya' da en çok ziyaret edilen işletmelerin bu mobil uygulamaları Türkiye'dekilere göre daha etkin bir şekilde ve daha fazla kullandığı fark edilmiştir. Cep telefonlarının günlük hayatta etkin bir şekilde kullanıldığ düşünüldüğünde tematik park işletmelerinin mobil uygulamaları kullanılabilir hale getirmelerinin yararlarına olacağı düşünülmektedir.

Çevreleyen alan bilgisi boyutu incelendiğinde, Dünya'da en çok ziyaret edilen işletmelerin web sitelerinin Türkiye' deki işletmelerin web sitelerinden toplamda daha az puan aldıkları ve bu konuda Türkiye'deki işletmelerin daha başarılı oldukları gözlemlenmiştir. Bu boyutta yer alan A4 kodlu işletme web sitesinin kullanılabilirlik acısından yeterli olmadığı bulgularda rastlanmıştır. Bu durum Dünya' daki en çok ziyaret edilen işletmelerin web sitelerinin toplamda daha az puan almasına neden olmuştur.

Müşteri iletişim bilgileri boyutu incelendiğinde, Dünya'da en çok ziyaret edilen işletmelerin web sitelerinin Türkiye' deki işletmelerin web sitelerinden toplamda daha az puan aldıkları ve bu konuda Türkiye'deki işletmelerin daha başarılı oldukları gözlemlenmiştir. Bu boyutta yer alan A4 işletmesi ile 
ilgili web sitenin kullanılabilirlik acısından yeterli olmadığı bulgularda rastlanmıştır. Bu durum Dünya'daki en çok ziyaret edilen işletmelerin web sitelerinin toplamda daha az puan almasına neden olmuştur.

Rezervasyon ve fiyat bilgileri boyutu incelendiğinde, Dünya' da en çok ziyaret edilen işletmelerin web sitelerinin Türkiye'deki işletmelerin web sitelerinden toplamda daha fazla puan aldıkları ve bu konuda daha başarılı oldukları gözlemlenmiştir. B5 ve B8 işletmelerinin web sitelerinde rezervasyon ve fiyat bilgileri ile ilgili boyuttaki içeriklere yer vermediği bulgularda rastlanmıştır. Bu durum Türkiye'deki işletmelerin bu boyutta daha az puan almasına neden olmuştur. Günümüz tüketicilerinin teknolojiyi kullanım alışkanlıklarına bakıldığında rezervasyon ve fiyat bilgilerinin web sayfasında yer alması hatta çevrim içi alışveriş imkanlarının da sağlanması işletmelerin yararına olacağı düşünülmektedir.

Web sitesinin yönetimi boyutu incelendiğinde, Dünya'da en çok ziyaret edilen işletmelerin web sitelerinin Türkiye'deki işletmelerin web sitelerinden toplamda daha fazla puan aldıkları ve bu konuda daha başarılı oldukları gözlemlenmiştir. Bu boyutta yer alan oturum açlabilirliği içeriğine bir işletme haricinde Türkiye'deki işletmelerin web sitelerinde yer vermedikleri bulgularda rastlanmıştır. Bu durum ise Dünya'da en çok ziyaret edilen işletmelerin daha fazla puan almasını sağlamıştır. Oturum açabilme seçeneği müşteri sadakatini de getirebilmesi dolayısıyla faydalı olacağı düşünülmektedir. Web sitesinin yönetimi boyutunda yer alan sanal tur içeriğine Türkiye'deki ve Dünya'daki işletmelerin gereken önemi göstermediği anlaşılmaktadır. Web site kullanıcıları için bu içeriğin kullanımı, önceden bilgi sahibi olmak ve ziyaret edecekleri alanı daha yakından tanımaları acısından yararlı olacağı düşünülmektedir.

Son yıllarda dünyada olduğu gibi Türkiye'de de tematik parkların sayıları artmaktadır. Ancak bu parklarla ilgili çalışmaların kısıtlı olduğu görülmektedir. Bu çalışmanın tematik park web sitelerinin durumunu ortaya koyması açısından faydalı olacağı düşünülmektedir. Gelecek çalışmalarda daha fazla sayıda tematik park web sitesini içeren çalışmalar yapılabilir. 


\title{
EXTENDED ABSTRACT
}

\section{Evaluation of Themed Park Companies Web Sites Using Content Analysis: Comparison of the Samples in the World and in Turkey}

\author{
Muhammet Emin Soydaş - Emrah Göz \\ Iskenderun Technical University
}

It is observed that the theme parks have started to play an important role in the increase in tourism demand. Themed parks can be expressed as areas that people visit to gain different experiences and have a good time by moving away from the environment in which they live. Theme parks have been defined as a unit of visitor attraction centers (Swarbrooke, 1995; Middleton, 1988). These areas may be areas with natural attractions, as well as buildings, areas or special events with or without man-made visitor attraction. Theme parks have some features that differentiate it from visitor attraction centres (Kemperman, 2000) such as;

- One-time entrance fee or one-to-one fee attractions

- Mostly man-made charms

- Requires high capital investments.

Theme parks are man-made, user-oriented, highly developed entertainment areas that require high investment (Pearce, 1988) and an escape area (Forrec, 2019). Theme parks create spaces with multiple themes, rather than offering a single theme (Adventure, Futuorism, International, Natural, Fantasy, History and Movie) (Wong ve Cheung, 1999).

With the development of technology since 1980's tourism industry also changes (Ho and Lee, 2007; Buhalis and Law, 2008). It is observed that the number of internet users in the world is increasing rapidly. The rapid development of the Internet has also increased the influence of social media and has become active in holiday decisions (Aymankuy et all. 2013). The development of information technologies and the Internet, the use of electronic distribution tools enable tourism businesses to exist in the market, and their effective use enables them to gain an advantage over competitors. One of the most important tools of the digital economy is websites. Web sites are a tool 
for businesses to exist in a virtual environment. Hence its design, usefulness, reliability, accessibility, etc. is important.

When the literature was searched, no study was found on the websites of the theme parks. Besides, there are a lot of studies on web pages of hotels (Karamustafa vd., 2002; Ranganathan ve Ganapathy, 2002; Jeong ve Oh, 2005; Law ve Cheung, 2005; Law ve Hsu, 2006; Kim, Ma ve Kim, 2006; Purnawan, 2011; Salem ve Cavlek, 2016; Ateş ve Boz, 2015; Islam ve Nevenka, 2016; Asmadili ve Yüksek, 2018), food and beverage (Moreo, Çobanoğlu ve DeMicco, 2007; Dalgın ve Karadağ, 2013; Özdipçiner ve Ceylan, 2017; Güdük ve Uca, 2017) and travel companies (Park, 2002; Hançer ve Ataman, 2006).

Considering the studies on the subject, it is revealed that websites have become one of the essential tools in terms of marketing today. Online purchases are increasing rapidly with changing consumer behavior. However, it is observed that consumers have different expectations from the website in online purchases and their importance levels have also changed. It can be said that websites have become the primary sources for consumers who intend to purchase any goods or services, so businesses that want to take part in the online market should consider these factors and their importance levels.

The main scope of this study is the theme parks websites. It is aimed to reveal the status of websites, which is one of the factors that determine the status of theme parks in the online market, which has been facing increasing interest in recent years. With this purpose websites of the world's and Turkey's top ten most visited theme park were evaluated and compared by content analysis.

The most visited theme park groups in the world were obtained from the "Global Attractions Atten-dance Report 2018" (TEA, aecom.com):

1.Walt Disney

2.Merlin Entertainment

3.Universal

4.Oct Parks China

5.Fantawild

6.Chimelong Group

7.Six Flags Inc.

8.Cedar Fair Entertainment

9.Seaworld Parks \& Entertainments

10.Paraques Reunidos 
Having no information about number of visitors in Turkey, top 10 theme parks with the most reviews on Tripadvisor were taken into account.

1.Antalya Aquarium

2.The Land of Legends Theme Park

3.Aqua Dream Water Park1

4.Istanbul Aquarium

5.Izmir Natural Life Park

6.Aqualand \& Dolphinland

7.Isfanbul

8.Water Planet Aqua Park

9.Dolphin Park Marmaris

10.Legoland Discovrey Centre

Thematic park web pages were evaluated by content analysis method in line with the list obtained. For this purpose, Islam and Nevenka's (2016) stuy for hotel websites criterias have been adapted to evaluate theme parks web sites.

The number of criteria under each dimension gives the total score of that dimension: Business Information (9), Surrounding area information (6), Customer contact information (10), Reservation and price information (7). When analyzing web pages, instead of using the names of the enterprises, it was preferred to code and give the results with these encodings. Therefore, the world's most visited theme park coded from A1 to A10, themed parks in Turkey coded from B1 to B10. While examining the web pages, 1 is given fort he existence of the criteria and 0 for non-existence. The evaluation of the websites was done by two researchers between 06.06.2019 and 20.06.2019, and then the margin of error was tried to be minimized by comparing them.

Web pages of the world's top ten thematic parks with the highest number of visitors were evaluated and A1, A2, A3 nad A9 coded theme parks have all the criteria in the business information dimension. A5, A6 and A10 have 8 of 9 criteria of the same dimension. In general, it can be said that the dimension of business information is included in web pages.

Surrounding area information includes short description of the area, usability of the map, definition for distances, explanation for areas of interest, weather information. It is seen that only the A3 coded theme parkwebsite has all the features of this dimension. 
Customer contact information dimension includes address, telephone information, e-mail, registration form, frequently asked questions, newsletter, announcements, suggestions, 24-hour online help and social media links. Non of the web pages have all 10 criteria of this dimension.

Reservation and price information dimension includes, price, online availability, online reservation, package-promotional product usage, special offers, accepted credit cards information, group promotions. A4 coded theme park web pages has non of the creria of this dimension but other 9 theme park web pages has all the criteria of this dimension. Reservation and price information dimension were stated as the most important dimension in Law nad Hsu (2006) and Law and Cheung (2005) researches and findings are as similar.

web site management dimension consists of photo album-gallery, multilanguage option, virtual tour, logon ability and search engine links. A1, A3, A6, A7 and A9 coded theme park web pages have $80 \%$ of these criteria.

The top ten theme parks web sites in Turkey were analysed and it is seen that there is only one theme park that has all the features of business information. B10 coded theme park has a web page with 100\% of all the features.

It is seen that only 1 theme park web page has all the features in the surrounding area information dimension, while other theme park websites have 5 out of 6 features.

Considering the dimension of customer contact information, the web pages of B1, B4, B5, B7, B10 coded theme parks have $100 \%$ of the criteria, B2, B3 and $\mathrm{B} 8$ coded theme park web pages have $70 \%$ of the criteria.

Considering the reservation and price information dimension, B5 and B8 coded theme park websites get 0 points and do not have any criteria of this dimension. In addition, B6, B9 and B10 coded web pages have all the features in this dimension.

In terms of website management, only B4 coded theme park has 4 out of 5 features, while other web sites have $60 \%$ of these dimensions.

As evaluated generaly web pages of theme parks in Turkey are not as succesful as top ten theme parks that most visited in the World.

Number of theme parks in Turket is also incresing. However, it is seen that studies on these parks are limited. 
It is thought that this study will be useful in revealing the status of theme park websites. In future studies, studies including more theme park websites may be conducted.

\section{Kaynakça / References}

Anfara, V. A Jr ve Mertz, N, T.(2006). Theoretical frameworks in qualitative research.

Ateş, U. ve Boz, M. (2015). Konaklama işletmelerinin web sitelerinin değerlendirilmesi: Çanakkale örneği. Ekonomi İsletme Siyaset ve Uluslararası İlişkiler Dergisi, 1(1), 6384.

Aymankuy, Y., Soydaş, M. E. ve Saçlı, Ç. (2013). Sosyal medya kullanımının turistlerin tatil kararlarına etkisi: Akademik personel üzerinde bir uygulama. Internationa lJournal of Human Sciences, 10 (1), 376-398

Bohur, E. ve Kirali, A. E. (2015). Impact of globalization and technology on marketing activities and sales channels in the tourism industry. PressAcademia Procedia, $1(1), 81-93$

Braun, P. (2002). Networking tourism SMEs: e-commerce and e-marketing issues in regional Australia. Information Technology \& Tourism, 5(1), 13-23.

Buhalis, D. ve Law, R. (2008). Progress in information technology and tourism management: 20 years on and 10 years after the Internet-The state of eTourism research. Tourism management, 29(4), 609-623.

Conyette, M. (2012). A framework explaining how consumers plan and book travel online. International Journal of Management and Marketing Research, 5(3), 57-67.

Dalgın, T. ve Karadağ, L. (2013). Restoran işletmeleri web sitelerinin içerik analizi: Marmaris-Bodrum örneği. Abant İzet Baysal Üniversitesi Sosyal Bilimler Enstitüsü Dergisi.

Éthier, J., Hadaya, P., Talbot, J. ve Cadieux, J. (2006). B2C web site quality and emotions during online shopping episodes: An empirical study. Information $\mathcal{E}$ Management, 43(5), 627-639.

Forrec. (t.y). Forrec is an experience design company. 10.06.2019 tarihinde www.forrec.com adresinden erişilmiştir.

Güdük, T. ve Uca, S. (2017). Evaluation of the websites of the first-class restaurants in terms of design and marketing activities. Revista de turism-studii si cercetari in turism, 23.

Hançer, M. ve Ataman, C. (2006). Seyahat acentalarında iletişim teknolojisinin kullanımı ve web sitelerinin değerlendirilmesi: Ege Bölgesi Örneği. Dokuzeylül Üniversitesi, Sosyal Bilimler Enstitüsü Dergisi, 8(3), 193-207 
Ho, C. I. ve Lee, Y. L. (2007). The development of an e-travel service quality scale. Tourism Management, 28(6), 1434-1449.

Hojeghan, S. B. ve Esfangareh, A. N. (2011). Digital economy and tourism impacts, influences and challenges. Procedia-Social and Behavioral Sciences, 19, 308-316.

Homburg, C., Koschate, N. ve Hoyer, W. D. (2005). Do satisfied customers really pay more? A study of the relationship between customer satisfaction and willingness to pay. Journal of Marketing, 69(2), 84-96.

Hsu, K., Zhu, Z. ve Agrusa, J. (2004). Turning click-through visitors into customers: A study of Chinese hotel websites. Journal of Hospitality E Leisure Marketing, 11(4), 81-91.

Ip, C., Law, R. ve Lee, H. A. (2011). A review of website evaluation studies in the tourism and hospitality fields from 1996 to 2009. International Journal of Tourism Research, 13(3), 234-265.

Islam, E., B., S. and Nevenka, C, (2016). Evaluation of hotel website contents: existenceimportance analysis. Journal of Hospitality and Tourism Technology, 7(4).

Jeong, M., Oh, H. ve Gregoire, M. (2005). The role of website quality in online hotel reservations. Information Technology in Hospitality, 4(1), 3-13.

Karamustafa, K., Biçkes, D. M. ve Ulama, Ş. (2002). Türkiye'deki konaklama işletmelerinin internet web sitelerini değerlendirmeye yönelik bir çalişma. Erciyes Üniversitesi İktisadi ve İdari Bilimler Fakültesi Dergisi, 19, 51-92.

Kemperman, A. (2000). Temporal aspects of theme park choice behavior: modeling variety seeking, seasonality and diversification to support theme park planning. Eindhoven: Technische Universiteit Eindhoven. https://doi.org/10.6100/IR542240

Kerlinger, F. N. (1986). Foundations of behavioural research. 3 rd Edition. New York. Cited in:

Kim, D. Y., Lehto, X. Y. ve Morrison, A. M. (2007). Gender differences in online travel information search: Implications for marketing communications on the internet. Tourism management, 28(2), 423-433.

Kim, W. G., Ma, X. ve Kim, D. J. (2006). Determinants of Chinese hotel customers'e-satisfaction and purchase intentions. Tourism Management, 27(5), 890-900.

Law, R. ve Cheung, C. (2005). Weighing of hotel website dimensions and attributes. ENTER içinde (s. 350-359).

Law, R. ve Hsu, C. H. (2006). Importance of hotel website dimensions and attributes: Perceptions of online browsers and online purchasers. Journal of Hospitality $\mathcal{E}$ Tourism Research, 30(3), 295-312.

Middleton, V. T. (1989). Marketing implications for attractions. Tourism Management, 10(3), 229-232. 
Moreo, A., Cobanoglu, C. ve De Micco, F. (2007). A comparative analysis of restaurant websites and hospitality school restaurant websites. Journal of Hospitality $\mathcal{E}$ Tourism Education, 19(3), 40-47.

Özdipçiner, N. S. ve Ceylan, S. (2017). Restoran işletmeleri internet siteleri içerik analizi: Denizli ili araştirmasi. Yalova Üniversitesi Sosyal Bilimler Dergisi, 7(14), 51-61.

Park, C. (2002). A content analysis of travel agency web-sites in Korea. Asia Pacific Journal of Tourism Research, 7(1), 11-18.

Park, C. H. ve Kim, Y. G. (2003). Identifying key factors affecting consumer purchase behavior in an online shopping context. International journal of retail $\mathcal{E}$ distribution management, 31(1), 16-29.

Pearce, P. L. (1988). Recent research in psychology. The Ulysses factor: Evaluating visitors in tourist settings. New York, NY, US: Springer-Verlag Publishing.

Purnawan, P. (2011). Evaluating websites by features: do independent hotels in Singapore get it right?. UNLV Theses, Dissertations, Professional Papers, and Capstones. 1102.

Ranganathan, C. ve Ganapathy, S. (2002). Key dimensions of business-to-consumer web sites. Information $\mathcal{E}$ Management, 39(6), 457-465.

Salem, I. E. B. ve Čavlek, N. (2016). Evaluation of hotel website contents: existence-importance analysis. Journal of Hospitality and Tourism Technology, 7(4), 366-389.

Shoemaker, S., Lewis, R. C. ve Yesawich, P. C. (2007). Marketing leadership in hospitality and tourism: Strategies and tactics for competitive advantage. Upper Saddle River, NJ: Pearson Prentice Hall.

Sun, P., Cárdenas, D. A. ve Harrill, R. (2016). Chinese customers' evaluation of travel website quality: A decision-tree analysis. Journal of Hospitality Marketing $\mathcal{E}$ Management, 25(4), 476-497.

TEA. (t.y). Main page. 30.08.2019 tarihinde www.aecom.com adresinden erişilmiştir.

Themed Entertainment Association (TEA) (2019). Global attractions attendance report https://www.aecom.com/wp-content/uploads/2019/05/Theme-Index-20184.pdf

Tripadvisor. (t.y). 2017-2018. TripBarometer global report. 22.04.2019 tartihinde https://www.tripadvisor.com/TripAdvisorInsights/w4594 adresinden erişilmiştir.

Türob. (2017). UNWTO 2017 turizm barometresi. 11.06.2019 tarihinde http://www.turob.com/tr/istatistikler/unwto-2017-turizm-barometresi adresinden erişilmiştir.

Waresocial (2019) Digital report. https://wearesocial.com/blog/2019/01/digital-2019-global-internet-use-accelerates (erişim: 18.10.2019) 
Wong, K. K. ve Cheung, P. W. (1999). Strategic theming in theme park marketing. Journal of Vacation Marketing, 5(4), 319-332.

Ziaullah, M., Feng, Y. ve Akhter, S. N. (2014). Online retailing: relationship among etailing system quality, e-satisfaction, e-trust and customers commitment in China. International Journal of Economics, Commerce and Management, 2(10), 1-17.

\section{Kaynakça Bilgisi / Citation Information}

Soydaş, M. E. ve Göz, E. (2020). Temalı park şirketlerinin web sitelerinin içerik analizi ile değerlendirilmesi: Dünyadaki ve Türkiye'deki örneklerin kıyaslanması. OPUS-Uluslararası Toplum Araştırmaları Dergisi, 16(31), 4404-4429. DOI: 10.26466/opus.735180 